\title{
Conceptions of elementary and high school teachers on biotechnology
}

E.M. Miranda; F.M. Chiari; A.C.R. Guerra; N.F. dos Santos; N.R.S. Bossolan; L.M. Beltramini

\author{
Centro de Biotecnologia Molecular Estrutural (CBME/CEPID/FAPESP) \\ Instituto de Física de São Carlos - USP, São Carlos, SP \\ e-mail: nelma@ifsc.usp.br
}

The progress in the areas of molecular biology and biotechnology has been demonstrating the importance of the teaching-learning of those subjects to students and teachers of the elementary and high school as well as to the society in general.

In this sense, the Scientific Dissemination Coordination of CBME has as objective contributes for the dissemination and learning of techniques and basic concepts in that area of the knowledge, in order to awake in the public the scientific interest and the critical sense related to these advances.

With the goal to offer elements for the elaboration of activities addressed to science teachers of elementary and high school, a survey of their conceptions on science and biotechnology was made. A questionnaire was applied to 30 teachers that participated in updating courses and training, being that 13 teachers belonged to the region of São Carlos city (SP), 8 belonged to the region of Campinas city (SP) and 9 belonged to Fortaleza city (CE).

The questionnaire was applied to the teachers in the beginning of the courses and it was composed of different types of questions, which allowed capturing their personal reflections about science, their knowledge on basic concepts of cell and molecular biology, and their opinions about the applications of the biotechnology.

In the analysis of the question What you think about using the modern biotechnology in the production of foods to increase its protein content, in order to turn it larger or to change its taste?, 57\% of the teachers agreed partially that this application is useful for the society, $52 \%$ agreed totally that the application is morally acceptable while $70 \%$ totally disagree as for the encouragement of this application.

Some conflicts presented in the registered answers reflect, in certain way, the conflict shown by the academic and scientific communities, as for the ethical aspects of some applications such as transgenic foods, genetic manipulation in animals and the possibility of human cloning.

\section{Supported by FAPESP e CNPq.}

